\title{
Fatigue behaviour of unidirectional carbon-cord reinforced composites and parametric models for life prediction
}

\author{
Y. Tao, E. Bilotti, J.J.C. Busfield \\ School of Engineering and Materials Science and the Materials Research Institute, Queen Mary University of \\ London, Mile End Rd, London, E1 4NS, UK \\ C. A. Stevens \\ NGF Europe Limited, Lea Green, St Helens, WA9 4PR, UK
}

\begin{abstract}
Unidirectional Carbon Cord reinforced HNBR composites (CF-HNBR) were prepared and fatigue tests under stress control were performed under non-relaxed tension-tension conditions. In this paper, various constant life diagrams (CLD) that are based on different theoretical formulations have been applied to the measured fatigue data of the CF-HNBR composites. The results show that the predictions made by piecewise CLD and modified Harries CLD produce the most accurate results. In addition, a novel experimental setup is described that replicates in a simplified way the real-pulley situation encountered under typical service conditions to investigate the effect of the bending curvature on the lifetime of the composite subject to coupled tension and bending conditions.
\end{abstract}

\section{INSTRUCTION}

Fibre reinforced composite materials are widely used in engineering applications. Hence, an accurate prediction of the service life of a composite structure is crucial. However, it is difficult to predict the lifetime because of material anisotropy and inhomogeneity compared to other isotropic material such as metal materials and other pure rubber materials (Busfield, 2011). A good understanding of the micromechanics of the composite failure process is required for life-prediction purposes. This has been studied extensively by Talreja (2015). For cord reinforced rubber material, the crack growth behaviour of the rubber matrix and peeling behaviour at the interface were investigated extensively by Busfield $(2000,2008,2012,2013)$. A number of cumulative damage models were proposed based on the fatigue damage induced by repeated loading which was reviewed by Socie and Morrow (1980) and Hwang and Han (1986). In the damage models, the damage function is defined as a certain material property that varies with the number of applied cycles and the applied stress level during fatigue, such as the residual modulus, resultant strain and residual strength. However, such methods require a detailed understanding of the way in which the fatigue damage affects the material's residual properties. In practice, the designer usually needs to assess the service life before this type of information is available. Therefore, another methodology based on the phenomenological modelling of the material is required. Various models such as the Linear CLD, Piecewise
Linear CLD (Philippidis et al., 2004), Harris's CLD (2003), Kawai's CLD (2015), Boerstra's CLD (2007) and Kassapoglou's CLD (2007) have all been proposed to address this. This approach has no identified physical mechanism of degradation as it is only based on a mathematical analysis of the fatigue data over a wide range of stress ratios. Care must be exercised as a singularity occurs from all compressive region to tensile-compressive regions where $\mathrm{R}$ jumps from $-\infty$ to $+\infty$. In addition, at $R=1$ (alternating stress equals zero), this type of loading could be considered as a constant creep load rather than a fatigue load (Vassilopoulos et al., 2010).

Moreover, the cord-rubber composites found in components such as a pneumatic tyre or a timing belt often undergo a combination of complex tension and bending deformations rather than in simple extension alone. And there appears a lack of scientific literature examining this type of fatigue loading.

In this paper, the applicability of five different CLD models on the CF-HNBR composites were evaluated. To apply this type of fatigue modelling to a real case incorporating both tension and bending will require closer interpretation of the stress states in the fibres that will use the results of the finite element analysis stress distributions presented in (Tashiro et al, 2017). 


\section{EXPERIMENTAL PROCEDURES}

\subsection{Materials}

Previously compounded HNBR was re-milled immediately prior to moulding using a 2-roll mill for 5 minutes and it was shaped into a flat sheet for compression moulding. This mixing also ensured an even dispersion of the additives after a relatively long storage time. The vulcanization behaviour was recorded using a rheometer (MDR2000, Alpha Technology, USA) at $180^{\circ} \mathrm{C}$ according to ASTM D3182. The cords were placed in between two pieces of rubber with a $5 \mathrm{~N}$ pretension attached to either end of the cord and then moulded using a hydraulic hot press at $180^{\circ} \mathrm{C}$ for $20 \mathrm{~min}$.

\subsection{Test procedures}

Tension-tension fatigue loading at $10 \mathrm{~Hz}$ : Carbon cord-HNBR specimens were subjected to a sinusoidal waveform under stress-controlled mode with each test being conducted to a constant maximum load for ranges of various positive $\mathrm{R}$ ratios and test frequencies. Five repeats were carried out under each condition.

Tension-bending coupling fatigue loading at $R=0.4$ : a novel experimental set-up was developed that replicates in a simplified way the real-pulley situation encountered under typical service conditions, as shown in Figure 1. The extent of bending strain in the test was achieved by using pulleys with different diameters $(20 \mathrm{~mm}, 30 \mathrm{~mm}, 40 \mathrm{~mm}$ and $50 \mathrm{~mm})$. The life-time was recorded as a function of the frequency and the stress level.

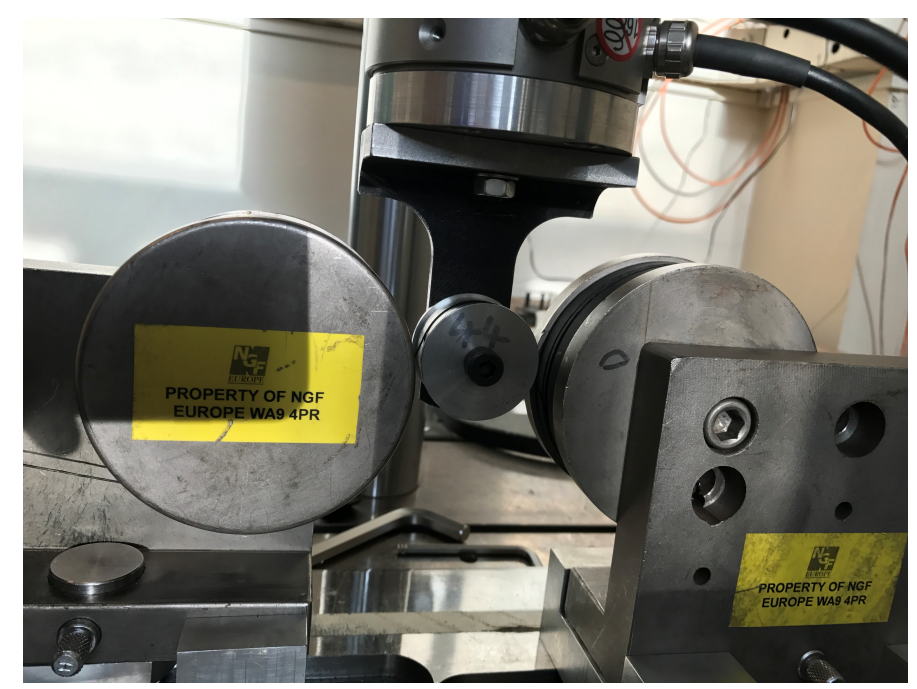

Figure 1: Testing setup for tension-bending coupling fatigue loading.

\section{RESULTS AND DISCUSSIONS}

\subsection{Tension-tension results and CLDs}

The commonly used parameters encountered in a fatigue test are all shown in Figure 1. The main parameters used in the constant life diagram in this paper were normalised stress amplitude, $a=\sigma_{a} / \sigma_{u}$, and normalised mean stress, $m=\sigma_{m} / \sigma_{u}$, where $\sigma_{u}$ was a reference stress level.

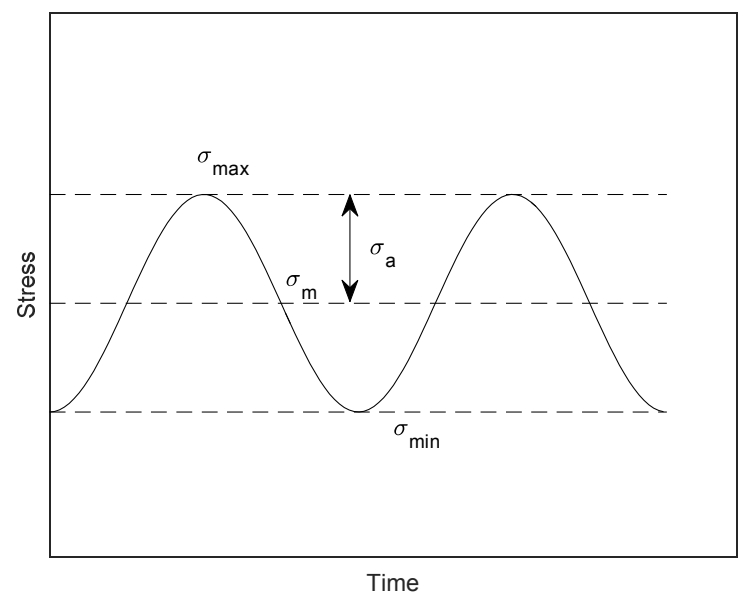

Figure 2: The definition of the commonly encountered test parameters used in this fatigue investigation.

The CLDs reveal the combined effect of the mean stress and alternating stress during fatigue testing. Five models based on different approaches were applied on the fatigue testing data of CF-HNBR composites. For the linear model, the fatigue data at $R=0.3$ is used while that at $R=0.3, R=0.5$ and $R=0.7$ was used to create the Piecewise Linear Model and the Harris Model. The main feature of Kawai Model is that it can be derived by the S-N data at the critical $R$ ratio $\psi_{\chi}$, defined as the ratio of the ultimate compressive strength to the tensile strength of the examined material. For CF-HNBR composite in this paper, $\psi_{\chi}=-0.01$. However, no fatigue data is currently available for this critical $R$ ratio. Therefore the fatigue data at $R=0.3$ which is the closest value to $\psi_{\chi}$ was used to construct the CLD. The Kassapoglou Model was generated by assuming the scale and shape parameters were the same as those of carbon cord in a two parameter Weibull distribution. 


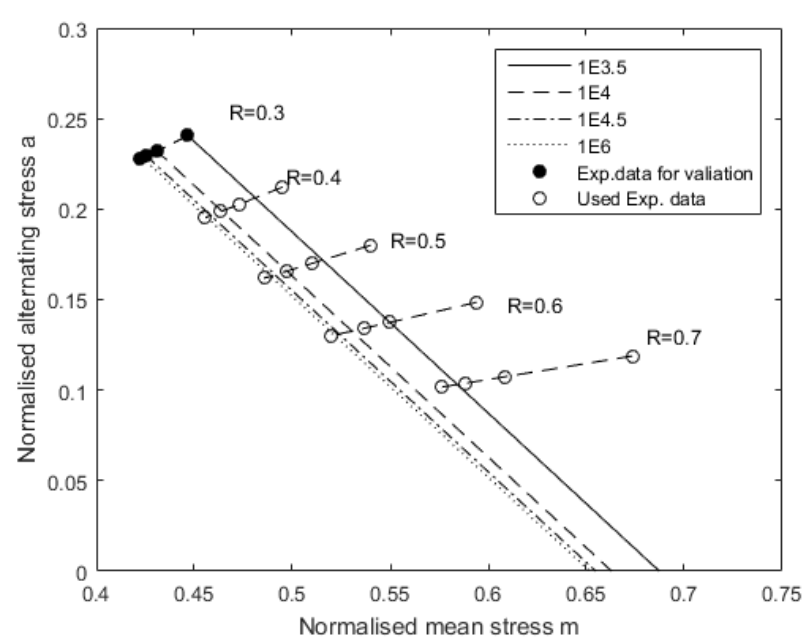

(a)

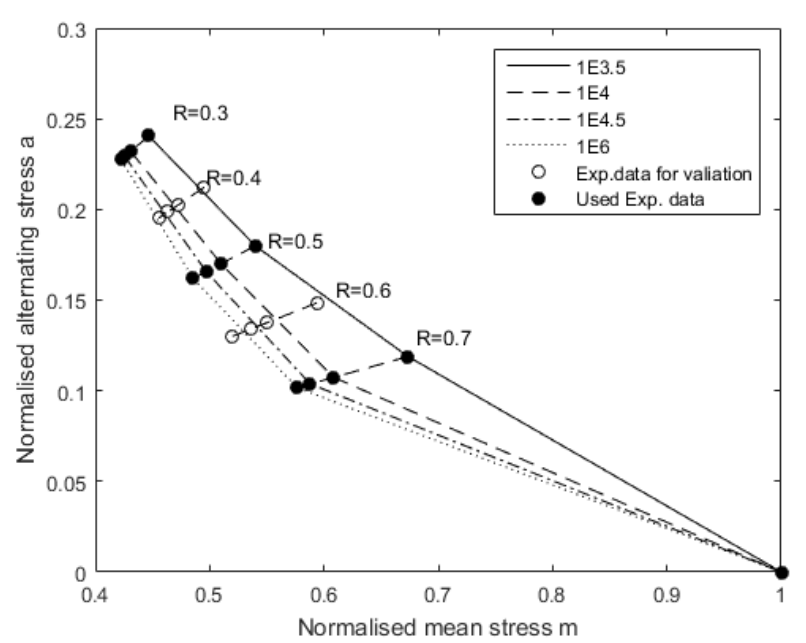

(b)

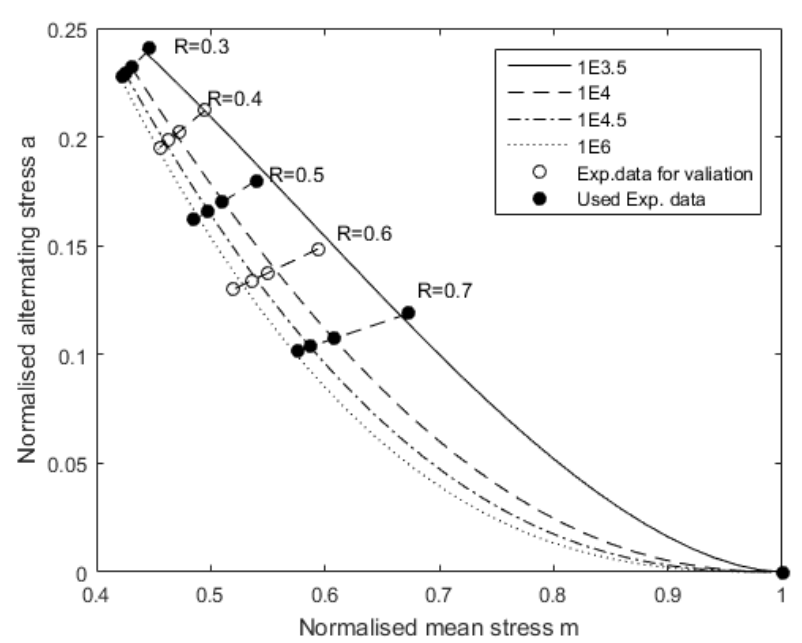

(c)

From Figure 3, it can be seen that the Piecewise Linear and Harris CLD gave accurate predictions compared to Linear CLD. However, Kawai's CLD failed to predict the lifetime and this might because

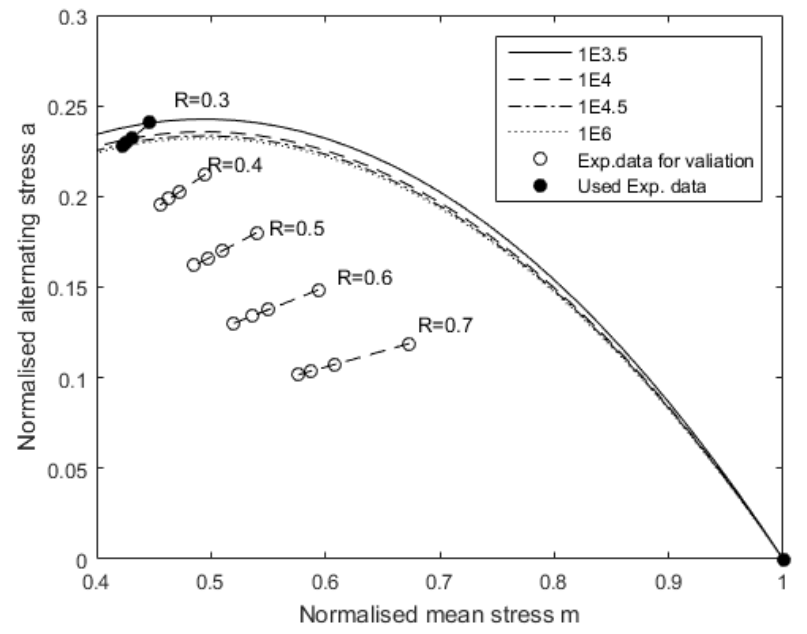

(d)

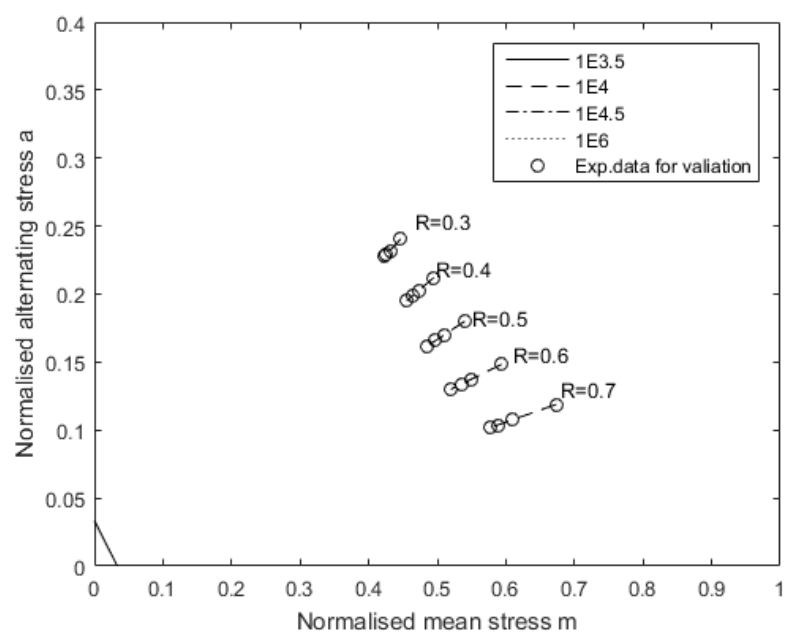

(e)

Figure 3: Different CLDs based on different approaches,

(a) Linear, (b) Piecewise Linear, (c) Harris, (d) Kawai, (e) Kassapoglou.

the improper usage of fatigue data at $R=0.3$ instead of data at the critical $R$ ratio. The Kassapoglou Model provided very poor results for these materials as it is based on parameter taken from the static behaviour which were not related directly to fatigue data.

\subsection{Tension-bending results}

The S-N curve of the coupled tension-bending test using the smallest $20 \mathrm{~mm}$ wheel (therefore with the greatest bending contribution) at $5 \mathrm{~Hz}$ are shown in Figure 4. The y axis is the normalised peak stress. Figure 5 shows the preliminary results of the influence of the bending curvature and the lifetime under the combination of tension and bending loading. The finite element study of the carbon cord in rubber under tension and bending conditions has also been studied (Tashiro et al., 2017).

It can be found that the bending fatigue life decreased with an increase in the bending curvature at certain percentage of the ultimate strength. A more 
comprehensive picture will be provided in the presentation when the full set of data becomes available.

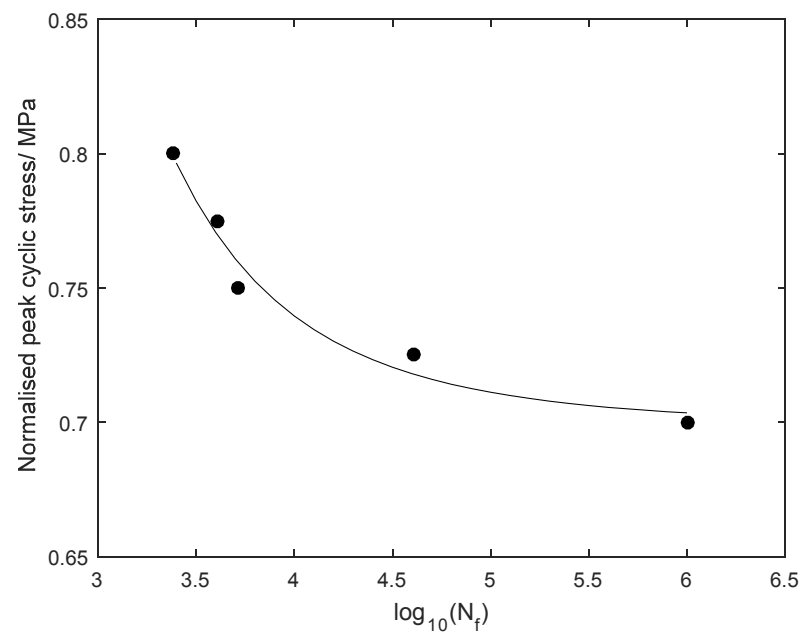

Figure 4: S-N curve of tension-bending coupling test on $20 \mathrm{~mm}$ wheel at $5 \mathrm{~Hz}$

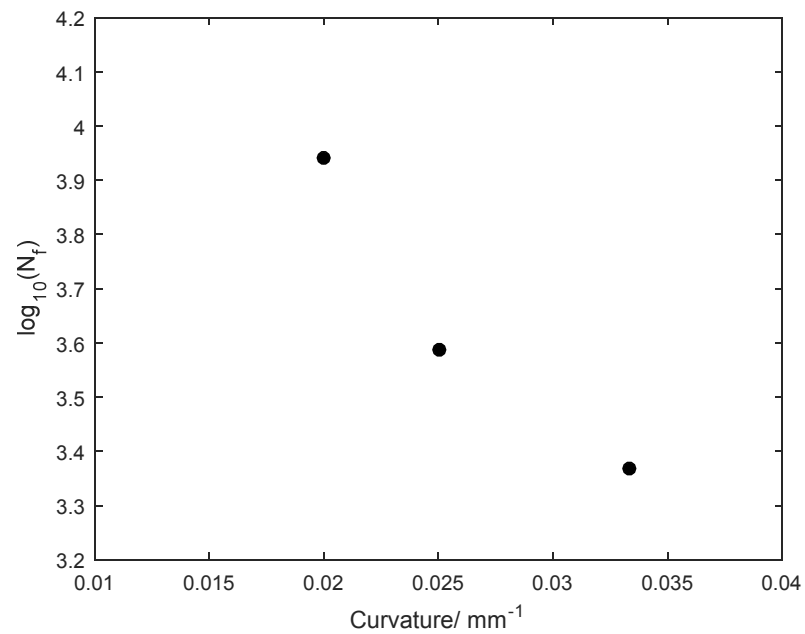

Figure 5: Preliminary results of the influence of the bending curvature and the lifetime.

\section{CONCLUSION}

Different CLDs were examined on the tensiontension behaviour of the CF-HNBR composites at various $\mathrm{R}$ ratios and the Harris's CLD and Piecewise Linear CLD turned out to be the most accurate ones for making a good life prediction.

Simple coupled tension and bending fatigue tests are currently still ongoing and data will be presented at the conference.

\section{ACKNOWLEDGEMENTS}

One of the authors, Yinping Tao would like to thank NGF for their financial support and for the supply of the various materials. She would also like to thank the China Scholarship Council for their financial support.

\section{REFERENCES}

ASARE, S. \& BUSFIELD, J. J. C. 2011. Fatigue life prediction of bonded rubber components at elevated temperature. Plastics, Rubber and Composites, 40, 194-200.

BOERSTRA, G. 2007. The Multislope model: A new description for the fatigue strength of glass fibre reinforced plastic. International journal of fatigue, 29, 1571-1576.

HARRIS, B. 2003. A parametric constant-life model for prediction of the fatigue lives of fibre reinforced plastics. Fatigue in Composites, 546-568.

HWANG, W. \& HAN, K. 1986. Cumulative damage models and multi-stress fatigue life prediction. Journal of Composite Materials, 20, 125-153.

KASSAPOGLOU, C. 2007. Fatigue life prediction of composite structures under constant amplitude loading. Journal of Composite Materials, 41, 2737-2754.

KAWAI, M. 2015. 8 - 2D woven fabric composites under fatigue loading of different types and in different environmental conditions. In: CARVELLI, V. \& LOMOV, S. V. (eds.) Fatigue of Textile Composites. Woodhead Publishing.

PAPADOPOULOS, I., THOMAS, A. \& BUSFIELD, J. 2008. Rate transitions in the fatigue crack growth of elastomers. Journal of applied polymer science, 109, 1900-1910.

PHILIPPIDIS, T. P. \& VASSILOPOULOS, A. P. 2004. Life prediction methodology for GFRP laminates under spectrum loading. Composites Part A: applied science and manufacturing, 35, 657 666.

TASHIRO R, YONEZAWA S, STEVENS C.A. Rubber reinforcing carbon fibre cord under tension and bending Part 1: Stress analysis. ECCMR2017.

SAKULKAEW, K., THOMAS, A. G. \& BUSFIELD, J. J. 2013. The effect of temperature on the tearing of rubber. Polymer Testing, 32, 86-93.

SOCIE, D. \& MORROW, J. 1980. Review of con-temporary approaches to fatigue damage analysis. Risk and Failure Analysis for Improved Performance and Reliability. Springer.

TALREJA, R. 2015. 1 - A conceptual framework for studies of durability in composite materials. In: CARVELLI, V. \& LOMOV, S. V. (eds.) Fatigue of Textile Composites. Woodhead Publishing.

TSUNODA, K., BUSFIELD, J., DAVIES, C. \& THOMAS, A. 2000. Effect of materials variables on the tear behaviour of a non-crystallising elastomer. Journal of materials science, 35, 5187-5198.

BAUMARD, T., THOMAS, A. \& BUSFIELD, J. 2012. Fatigue peeling at rubber interfaces. Plastics, Rubber and Composites, 41, 296-300.

VASSILOPOULOS, A. P. 2010. Influence of the constant life diagram formulation on the fatigue life prediction of composite materials. International journal of fatigue, 32, 659-669. 